\title{
Assessing Effects of Energy Development in Colorado and New Mexico
}
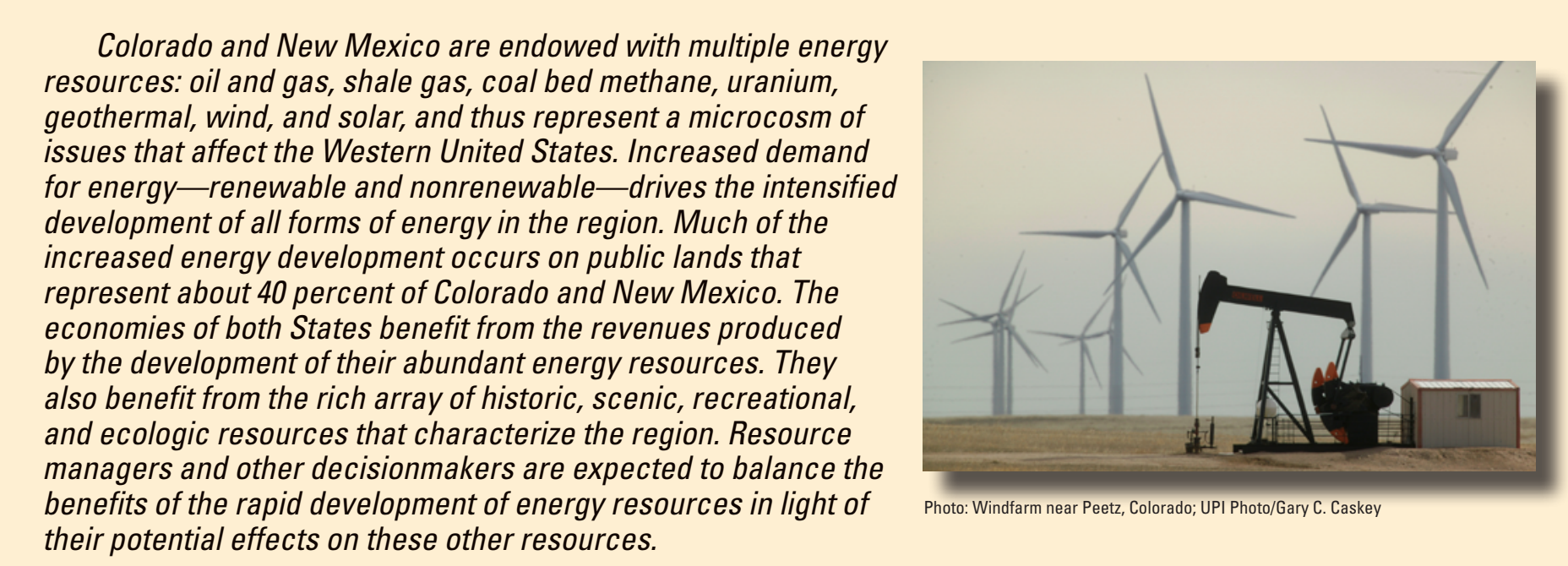
their potential effects on these other resources.

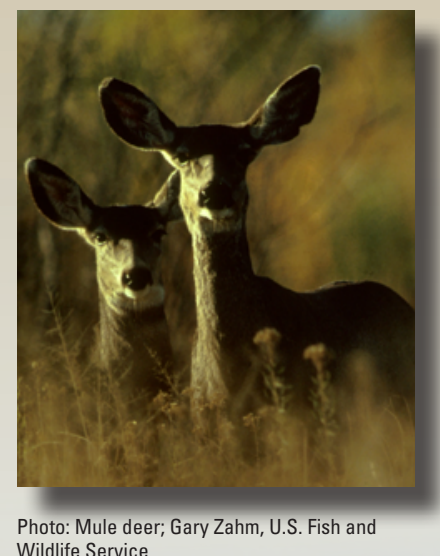

\section{A Context for Decisionmaking}

Decisionmakers in Colorado and New Mexico-in Federal, State, and local governments, as well as in the private sectorneed to make choices about developing or preserving sometimes competing resources. They currently make these decisions without the benefit of an integrated analysis to understand the cascade of effects from the various decision alternatives. Although aspects of the environmental implications of energy development have been studied, information is not synthesized in ways useful to decisionmaking. Resource managers would like to plan ahead and anticipate decisions so they can evaluate the potential consequences and tradeoffs of management options. By collaborating with decisionmakers to identify the most pressing information needs, an interdisciplinary team of scientists with the U.S. Geological Survey (USGS) will tailor analyses and develop a framework to best meet decisionmaking needs.

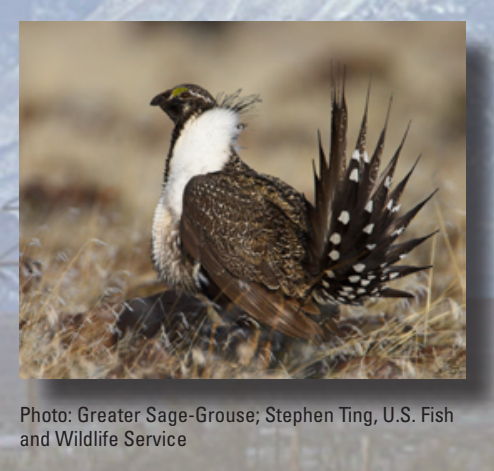

\section{A Framework for Analysis}

USGS scientists will evaluate the environmental effects of energy development by using a multistep process - or framework - designed to allow decisionmakers to compare the cumulative effects and tradeoffs produced by different mixes of energy development. The evaluation will begin with estimates of the potentially available energy resources in Colorado and New Mexico. USGS produces energy resource assessments for nonrenewable energy resources (oil and gas, coal, uranium, and oil shale), which will serve as the basis for these estimates. Quantifying potentially available energy resources will make it possible to estimate the amount of supporting infrastructure associated with development and extraction of a given type of energy resource. This analysis can include, for example, an estimate of the likely number of well pads anticipated for extraction of the oil and gas resources from a field, or the number of wind turbines required to meet State electricity production goals.

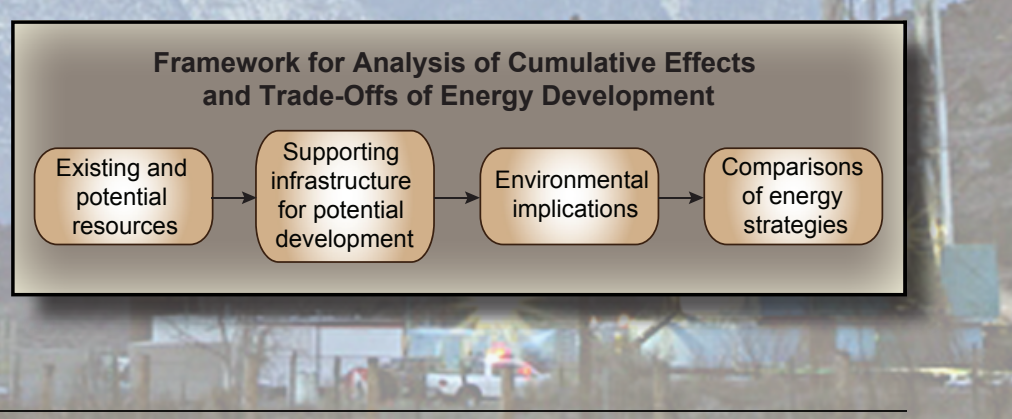


The required infrastructure for each different energy type has environmental implications. For example, wellpad density for oil and gas development has implications for water use and production, road networks to service the wells, and potential habitat fragmentation. Similarly, the infrastructure requirements for a wind facility include turbines, access roads, buried electrical cables, and a connection to the larger electrical grid. Developing a framework for analysis of the various energy types and the environmental implications of their development will allow decisionmakers to compare multiple energy strategies and scenarios that involve different mixes of energy types.

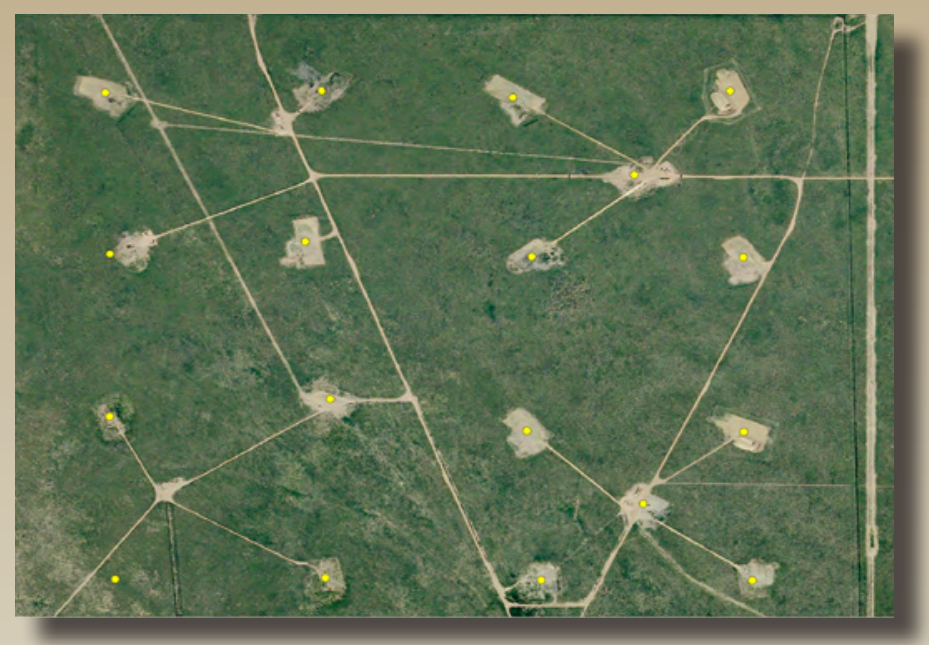

Surface disturbance from oil and gas wells in one square mile, Weld County, Colorado. Modified from 2009 imagery provided by the National Agriculture Imagery Program.

\section{An Interactive Energy Atlas}

The framework for analysis of the various energy types and the environmental implications of development will be synthesized in the form of an Interactive Energy Atlas for Colorado and New Mexico. The Atlas will be a distillation of key information in formats that allow decisionmakers to evaluate and compare the potential benefits and tradeoffs associated with different energy strategies or scenarios. Baseline information from current energy development in the region will be included-for both renewable and nonrenewable energy sources - so that a characteristic "footprint" or affected area for each energy type can be projected to undeveloped areas with potential for similar energy development. Providing this interactive resource will assist decisionmakers in anticipating potential consequences of each type of energy development and in making choices or developing mitigation strategies once they assess the possible environmental implications as new development is proposed.

Interactive maps, downloadable data layers, complete metadata, and decision-support tools will be included in the Energy Atlas. This format is intended to facilitate the integration of information about energy with key terrestrial and aquatic resources for evaluating tradeoffs of energy development and identifying areas with energy potential, as well as potential risks to other resource values.

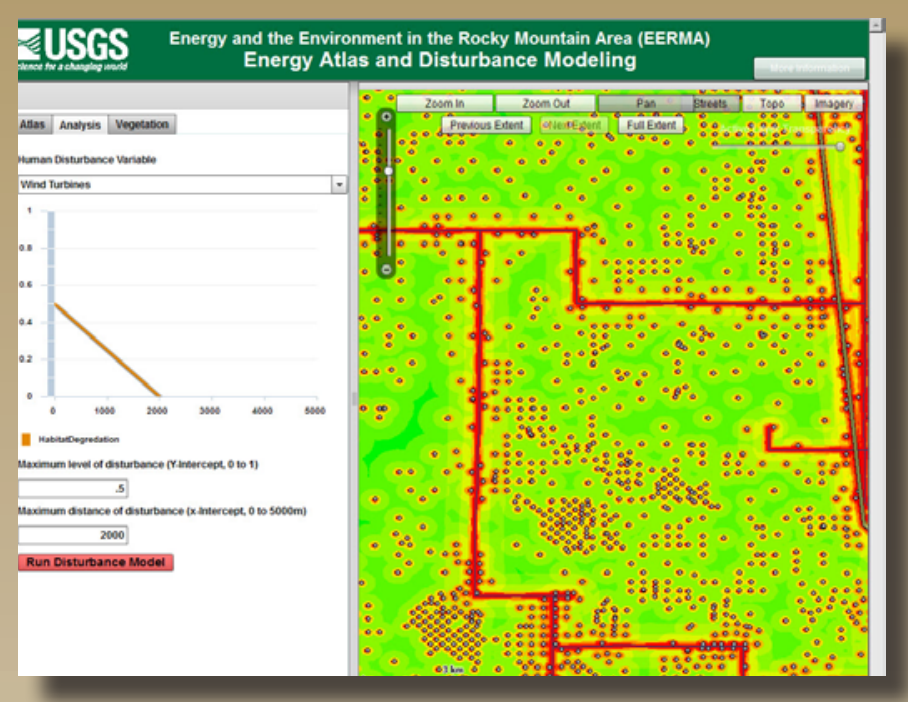

Online Interactive Energy Atlas can be used to evaluate energy footprints.

The Energy Atlas will be a dynamic product. Continued collaboration with decisionmakers to assess their changing needs - and the addition of new information from ongoing research in the area of infrastructure "footprints"-will guide on-going analyses and refinement of the Atlas. Anticipated is an evolving, up-to-date and interactive Energy Atlas for decisionmakers, designed to help them address the developing energy picture for the region. The Energy Atlas will thus inform the dialog about future energy development in a region striving to maintain its rich natural heritage while capitalizing on its unique energy potential.

The ultimate goal of our effort is to develop decision support tools that allow decisionmakers to evaluate energy development scenarios using the information contained in the Energy Atlas. Collaboration with decisionmakers is essential to ensure that these decision-support tools are tailored to their needs.

\section{Contact Information}

Tasha Carr
Fort Collins Science Center
carrn@usgs.gov
970.226.9446
Jay Diffendorfer
Rocky Mountain Geographic
Science Center
jediffendorfer@usgs.gov
303-202-4070
Ken Leib
Colorado Water Science Center
kjleib@usgs.gov
970.245.5257

\section{Natalie Latysh Core Science Systems nlatysh@usgs.gov 303.202.4637}

\section{Anne-Marie Matherne New Mexico Water Science Center matherne@usgs.gov 505.830.7971 \\ Christine Turner \\ Central Energy Resources \\ Science Center \\ cturner@usgs.gov 303.236.1561}

